http://jmscr.igmpublication.org/home/ ISSN (e)-2347-176x ISSN (p) 2455-0450

crossref DOI: https://dx.doi.org/10.18535/jmscr/v8i5.15

Journal Of Medical Science And Clinical Research

\title{
Comparative Study of External Dacryocytorhinostomy and Endonasal Endoscopic Dacryocystorhinostomy
}

\author{
Authors \\ Dr Shruti Chaudhary ${ }^{1}$, Dr Vijay Bhaisare ${ }^{2}$, Dr Preeti Rawat ${ }^{3}$, Dr S. Walia ${ }^{3}$, \\ Dr Neetu Kori ${ }^{3}$, Dr Sanchiyka Thakur ${ }^{3}$ \\ ${ }^{1}$ PG Resident Dept of Ophthalmology, MGM medical college Indore MP 452001 INDIA \\ ${ }^{2}$ Professor Dept of ophthalmology MGM Medical College Indore MP India
}

\begin{abstract}
Background: stenosis of nasolacrimal duct with the resultant stagnation of lacrimal fluid and subsequent infection is the most common cause of dacryocystitis. Dacryocystorhinostomy stands as the gold standard in treatment of chronic dacryocystitis. It can be performed via 2 approaches: External and Endonasal.

Aim: This study was done to compare the This study was done to compare the success rates and merits and demerits between External DCR and Endonasal Endoscopic DCR

Method: It was a single-center prospective randomized comparative interventional study completed in the duration of two years done in the Upgraded Department of Ophthalmology \& Department of Otorhinolryngology of MGMMC \& MY Hospital. A total of 40 cases with chronic dacryocystitis presenting with NLD obstruction based on symptomatic, clinical and radiologic grounds were included in the study and divided randomly into 2 groups. Each group subjected to External and Endoscopic DCR respectively.

Result: There were no significant difference in success rates between both the groups. However variation was noted in merits and demerits of both the techniques of external and endonasal DCR.The study revealed that after a mean follow-up of 3 months, difference in success rates (patency) between these groups were statistically insignificant $\left(X^{2}\right.$ test $\left.=2.264, P=0.322\right)$.(Table 3 )

Conclusion: Although statistically insignificant, At the end of 3 months follow-up period, the success rate was highest in External DCR (90\%) in comparison to Endoscopic DCR (80\%). But Endoscopic DCR is a minimally invasive scarless surgery with cosmetically more acceptable by young patients and has less intraoperative bleeding as it is a direct approach to the lacrimal sac.
\end{abstract}

Keywords: dacryocystorhinostomy, dacryoscytitis, nasolacrimal duct.

\section{Introduction}

Dacryocystorhinostomy (DCR) has been considered as the standard procedure for treatment of acquired nasolacrimal duct obstruction (NLDO), in which an anastomosis is created between the lacrimal sac and nasal cavity by removing the bone that separates these two structures and bypass the occluded nasolacrimal duct of the downstream.

DCR which was first described by Toti in 1904, is still gold standard procedure owing to its high success rate ${ }^{1}$. Though over time several modifications have been introduced to overcome the various issues in original technique such as 
prolong operative time and post operative visible scar.

DCR can be performed by 2 routes: (i) conventional route through transcutaneous incision, (ii) endoscopic endonasal route without disrupting the neurovascular plane.

Caldwell in 1893, first described Endonasal dacryocystorhinostomy but did not gain much success because of the poor monocular view but with the introduction of endoscope permitting direct adequate visualization, this approach gained considerable popularity in last two decades.

\section{Material and Method}

This is scientific and ethical committee approved prospective, comparative, interventional study. A total of 40 diagnosed cases of chronic dacryocystitits (due to NLDO) within age group of 18-70 yrs were randomly divided into 2 equal groups. $1^{\text {st }}$ group included those patients in whom Conventional DCR was performed and $2^{\text {nd }}$ group included patients of Endocopic DCR Patient with acute dacryocystitis, post traumatic bone deformity, fibrosis, malignancy of sac or bleeding disorder were excluded from the study. Participants included in the study underwent anterior segment evaluation by slit lamp, regurgitation test, lacrimal sac syringing and probing, routine blood investigation, imaging studies like X-ray PNS, Dacryocystography and ENT evaluation.

\section{Surgical Technique}

$\square$ 1st group after preoperative nasal packing and LA, underwent external DCR through incision of $8 \mathrm{~mm}$ size on the side of the nose below the medial canthal tendon, and the dissection was carried down to bone, after cutting MPL. The periosteum was reflected from the anterior lacrimal crest to reveal the lacrimal sac fossa. The sac was then reflected laterally. The nose was entered by pushing a blunt instrument through the suture line between the lacrimal bone and the frontal process of the maxilla. Kerrison punches were used to remove bone between the sac fossa and the nose, to create an opening large enough to anastomose the sac and nasal mucosa. Flaps were created in the medial sac wall and in the adjacent nasal mucosa. The posterior flaps and then the anterior flaps of the sac and nasal mucosa were sutured together to form a mucosa-lined tunnel across the ostium. ${ }^{2,3}$

- In $2^{\text {nd }}$ endoscopic group, patient was prepared bylocal infiltration of middle turbinate, axilla and adjacent lateral wall done using $2 \%$ xylocaine with $1: 1,00,000$ adrenaline and nasal decongestion by $0.1 \%$ xylometazoline.

U Under GA using nasal endoscopic visualization, superior incision was made using scalpel blade or cautery probe horizontally 8-9 $\mathrm{mm}$ above the axilla of the middle turbinate extending anteriorly up to frontal process of axilla and vertically just above the insertion of inferior turbinate. Inferior incision from the insertion of the uncinate was made to join the vertical incisionand posteriorly based mucosal flap was made to expose the lacrimal bone. Lacrimal bone was removed using kerrison punch to expose lacrimal sac followed by vertical incision along the entire length of the lacrimal sac from the fundus down to the nasolacrimal duct. The lacrimal sac was then completely marsupialized and both the anterior and posterior sac flaps were laid opened and flat like an open book on the lateral nasal wall. Returned the remainder of the flap onto the lateral wall and ensured that the exposed bone was covered. Nasal cavity was packed using antibiotic soaked gauze pack or merocele. ${ }^{3,4}$

Post operative Oral Antibiotics \& Antiinflammatory drugs were started for 5 days along with decongestive nasal drops and topical antibiotics.

Success of surgery was assessed post operatively on $7^{\text {th }}$ day, 15th day, 1 month and 3 months by checking anatomic patency through lacrimal sac 
syringing . Analysis of study was done using chi square test.

\section{Results}

A total of 40 cases of chronic dacryocystitis with NLD block and varied presentation were consented with mean follow up of 3 months.(Table 1)

There were $5(25 \%)$ males and 15(75\%) females in group 1 and 6(30\%) males and 14(70\%) females in group 2.

Difference in gender distribution among the groups was not significant. $\left(\mathrm{X}^{2}\right.$ test $=0.1642$, $\mathrm{p}=0.9212$ ).

In group 1 Mean age of patient was $44.25( \pm 8.3)$ years with range of 29-61yrs. In group 2 mean age was 34.35 ( \pm 10.6$)$ years with range of $19-55$ yrs. The age difference between the groups was not significant. $(p=0.603)$. There were no significant differences between the two groups for age and gender though demographic profile of the three groups showed a female predominance in each group with mean age in the range of 18 to 70 years.

Intraoperative excessive bleeding from nasal mucosa in EX DCR group was $60 \%$ and $20 \%$ in EN DCR group. Also difficulty in localization of sac was $35 \%$ in EX DCR and $10 \%$ in EN DCR. Difference in intraoperative complication was not significant $(\mathrm{p}=0.42)($ Table 2$)$

Anatomical success at the end of $3^{\text {rd }}$ month was achieved in 18(90.0\%) cases for EX- DCR and 16 $(80.0 \%)$ cases for EN-DCR.

There was no statistically significant difference regarding anatomical success rate (patency) between these groups $\left(\mathrm{X}^{2}\right.$ test $\left.=2.264, P=0.322\right)$. (Table 3)

Table 1 Incidence of various modes of presentation

\begin{tabular}{|l|c|c|c|c|}
\hline Modes of presentation & \multicolumn{2}{|c|}{ Group 1 } & \multicolumn{2}{c|}{ Group 2 } \\
\hline epiphora & 20 & $100 \%$ & 20 & $100 \%$ \\
\hline mucocele & 3 & $15 \%$ & 1 & $5 \%$ \\
\hline discharge & 8 & $40 \%$ & 6 & $30 \%$ \\
\hline Nasal obstruction & 6 & $30 \%$ & 7 & $35 \%$ \\
\hline fistula & 0 & 0 & 0 & 0 \\
\hline
\end{tabular}

Table 2 Incidence of Complications

\begin{tabular}{|l|c|c|c|c|}
\hline Complication & \multicolumn{2}{|c|}{ Group 1 } & \multicolumn{2}{c|}{ Group 2 } \\
\hline Intraoperative & & & & \\
\hline Excessive bleeding & 12 & $60 \%$ & 4 & $20 \%$ \\
\hline Difficulty in localization of sac & 7 & $35 \%$ & 2 & $10 \%$ \\
\hline postoperative & & & & \\
\hline Periorbital pain $\left(1^{\text {st }}\right.$ wk) & 20 & $100 \%$ & 20 & $100 \%$ \\
\hline Periorbital swelling $\left(1^{\text {st }}\right.$ wk) & 20 & $100 \%$ & 14 & $70 \%$ \\
\hline Suture abscess & 4 & $20 \%$ & 0 & 0 \\
\hline Epistaxis & 1 & $5 \%$ & 2 & $10 \%$ \\
\hline
\end{tabular}

Table 3 Follow up

\begin{tabular}{|c|c|c|c|c|c|c|c|c|}
\hline parameters & \multicolumn{4}{|c|}{ Group 1 } & \multicolumn{4}{|c|}{ Group2 } \\
\hline Weeks & $1^{\text {st }} \mathrm{wk}$ & $2^{\text {nd }} w k$ & $4^{\text {th }} \mathrm{wk}$ & $12^{\text {th }} \mathrm{wk}$ & $1^{\text {st }} \mathrm{wk}$ & $2^{\text {nd }} \mathrm{wk}$ & $4^{\text {rd }} \mathrm{wk}$ & $12^{\text {th }} \mathrm{wk}$ \\
\hline$\frac{\text { Sac syringing }}{\text { Patent }}$ & 20 & 18 & 17 & 17 & 19 & 18 & 16 & 16 \\
\hline Obstructed & 0 & 2 & 3 & 3 & 1 & 2 & 4 & 4 \\
\hline $\begin{array}{l}\text { Subjective } \\
\text { assessment }\end{array}$ & & & & & & & & \\
\hline Pain & 20 & 18 & 06 & 05 & 20 & 20 & 15 & 08 \\
\hline Epiphora & 08 & 06 & 03 & 03 & 04 & 03 & 03 & 03 \\
\hline
\end{tabular}


Table 4 Success Rate

\begin{tabular}{|l|c|c|c|c|}
\hline \multirow{2}{*}{ OUTCOME } & \multicolumn{2}{|c|}{ External DCR } & \multicolumn{2}{c|}{ Endoscopic DCR } \\
\cline { 2 - 5 } & No. & $\%$ & No. & $\%$ \\
\hline Successful & 18 & 90 & 16 & 80 \\
\hline Failure & 02 & 20 & 04 & 20 \\
\hline Total & 20 & 100 & 20 & 100 \\
\hline
\end{tabular}

\section{Discussion}

In our study incidence of dacryocystitis due to NLDO in females was $70-75 \%$ and in males was 25-30\% (3:1). This correlated with the study of Dolman et a (2003) (Female:male ratio 3:1) and Duke elders who observed similar incidence of $75-80 \%$ in females and $20-25 \%$ in males. ${ }^{6}$ This finding could probably be attributed to narrower lacrimal fossa in females predisposing to obstruction as stated by Jorge et al. ${ }^{7}$

The mean age in our study was $44.25( \pm 8.3)$ years in $1^{\text {st }}$ group, and $34.35( \pm 10.6)$ year in group $2^{\text {nd }}$ Wormald et al (2003) found average age of presentation to be 59 years $^{8}$ while Weidenbecher et al (1994) in their study observed maximum incidence between $50-80$ years. ${ }^{9}$ Our observation did not corroborate with literature studies, which may be attributed to small sample size.

The success rate of external DCR has been reported at $90 \%$ to $97 \%$, depending on the surgeon's experience by Olver JM et al (2003). The success rate of endoscopic DCR has been reported between $82 \%$ to $86 \%$ (Rice DH et al, 1990; Shun Shin et al, (1998). In our study external DCR had a success rate of $90 \%$ and endoscopic $80 \%$ although difference was statistically insignicant yet reported success rate in the literature correlates with our study.

Intraop complication vis. excessive bleeding from nasal mucosa was found in $60 \%$ and $20 \%$ patients and difficulty inlocalization of sac was encountered in $35 \%$ and $10 \%$ respectively in group 1 and group 2. Intraoperative bleeding was found to be less in Endoscipic DCR compared to EX DCR. ( $p=0.0098)$. This finding corroborated with study done by Moras et al.

\section{Conclusion}

Although success rates of both the surgeries are comparable, endoscopic DCR has an added advantage of avoidance of cutaneous scar, cosmetically more acceptable by young patients, less intraoperative bleeding while simultaneously allowing correction of any intranasal pathology over EX DCR , but it has certain drawbacks like provision of expensive instrumentation, risk of complication of anaesthetic drugs (GA).

Also external DCR has many advantages over EN DCR like small, no requirement of nasal packing, short learning curve, long term patency of ostium. So the choice of surgery should depend upon patient's preference, availability of resources and surgeon's expertise.

\section{Limitations}

Being a small sample size, results obtained from the study may be insufficient to draw conclusion on firm grounds

\section{Reference}

1. Toti A. Nuovo metodo conservatore di cura radicale delle suporazioni chroniche del sacco lacrimale. Clin Mod Firenze 1904;10:385-9.

2. Parson's Diseases of Eye, Diseases of Lacrimal Apparatus, pg 462-469.

3. Yanoff M, Ducker JS: The Lacrimal drainage system pg 1346, 4th ed

4. McDonough M, Meiring JH. Endoscopic transnasal dacryocystorhinostomy.

5. J Laryngol Otol 1989; 103: 585-7.

6. Duke-Elder $\mathrm{S}$ ed. System of Ophthalmology part II. 2nd ed. London: Henery Kimpton publishers;1974:568-718

7. Jorge GC, Alfanso UB. Nasolacrimal duct obstruction e medicine feb 9 2012; 
URL:http://emedicine.medscape.com/articl e/1210141-overview\#a0104

8. Tsirbas A, Wormald PJ: Mechanicl endonasal dacryocystorhinostomy with mucosal flaps. Br J. Ophth. 2003, 87:4347.

9. Weidenbecher M, Hosemann W, Wolfgang Buhr: Endoscopic endonasal dacryocystorhinostomy. 